\title{
Analysis on the Development of Cross-Border Electricity Suppliers in Guangdong Province under the Background of "One Belt and One
}

\author{
Road" \\ Zhu Wenbohao ${ }^{1 a}$, Sun $\mathrm{Bo}^{2 \mathrm{~b} *}$ \\ ${ }^{1}$ School of Economics and Trade, Guangdong University of Foreign Studies, Guangzhou, \\ Guangdong Province, China \\ ${ }^{2}$ Collaborative Innovation Center for 21st-Century Maritime Silk Road Studies, Research Institute \\ of International Services Outsourcing, Guangdong University of Foreign Studies, 2 North Baiyun \\ Avenue, Guangzhou,China

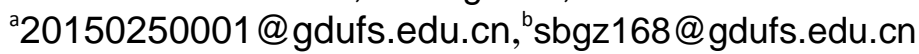

Key Words: cross-border electricity suppliers, Guangdong, "One Belt and One Road"

\begin{abstract}
With the recent implementation of the strategy “One Belt and One Road” in China, cross-border e-commerce has developed significantly. The fast development of cross-border electricity suppliers in Guangdong makes it an important study topic. This paper analyzes the development of cross-border electricity suppliers in Guangdong Province under the background of “One Belt and One Road” and their traditional modes and new changes, and it predicts the tends of market development in the e-commerce industry in the hope of providing a valuable guide for business leaders and academicians.

The 2015 implementation of "One Belt and One Road" strategy has brought a wide range of opportunities for the development of cross-border electricity suppliers, especially Guangdong Province. In that year, the volume of import and export trade for Guangdong's cross-border e-commerce was 16.73 billion Yuan, an increase of 3.6 times than the previous year. In 2015 Guangdong continued its role as the largest province in China involved in cross-border electricity commerce. The exports to the ASEAN, Europe and America were also kept high levels.
\end{abstract}

\section{Analysis on the Development of Cross-border Electricity Suppliers in Guangdong Province under the Background of "One Belt and One Road"Analysis on Policy Factors}

In July 2014, the General Administration of Customs issued Document Numbers 56 and 57 in the field of cross-border e-commerce to promote cross-border import and export business and facilitate customs clearance. This action acknowledged cross-border e-commerce as part of national policy. In 2015, as its executive meeting, the State Council launched a series of policies to reduce pilot import tariffs, reform taxes and increase duty-free ports, all reflecting the government's determination to promote domestic economic growth.

Guangdong launched the first domestic guiding policy document for cross-border electricity suppliers (cross-border e-commerce constructive plans for business parks in Guangdong Province) that focused on promoting cross-border e-commerce logistical service networks of public projects, cross-border e-commerce training programs, and other related cross-border e-commerce exchange activities and e-commerce projects in Guangdong province.

The Guangdong Provincial Department of Commerce supported the designation of pilot cities to promote cross-border trade and e-commerce services, and it has the most of number of cities as 
pilots for cross-border electricity business including Shenzhen, Dongguan, Jiangmen, Foshan, Zhuhai and other cities.

In addition to these supportive polices, in the fields of laws and regulations, cross-border electricity suppliers are also free of industry constraints and stringent regulations. Guangdong's e-commerce has experienced customer complaints, fake products and other consumer issues.

\section{Analysis on Infrastructure Environment}

Guangdong made many efforts to create a hardware environment to build strong off line activities and online platforms, such as organizing “cross-border electricity suppliers' exhibitions.

In logistics, Guangdong's cross-border e-commerce logistics can be classified into postal parcels, international and domestic express, green logistics, warehousing and other overseas shipping methods. Many high-speed rail ways, airports, ports and other infrastructure projects were launched throughout Asia, Europe and Africa. The completion of several major railways greatly improved the international logistics. Because Guangdong is located in the Pearl River Delta, it is able to clear customs once with both internal and external procedures to facilitate logistics and transport.

In Guangzhou, many cross-border electricity suppliers are trying to follow the new model of industrial parks, in which suppliers use green logistics to transport parcels abroad in contracted air cabins.

\section{Analysis on Supply Chain}

Although, cross-border e-commerce in Guangdong is rapidly growing, problems in the supply chain are still a bottleneck restricting the advancement of the cross-border electricity. Supply chain management for e-commerce is different from traditional logistics management in the fields of inventory management, logistics, cost, information flow, risk and the relations between organizations. At this stage, the lack of professional management teams, operational abilities, and industry resources have confused suppliers, and the industry has not yet formed an integrated supply chain to respond to customer demand in a fast, flexible and coordinated way.

In addition, there are a large number of popular products, which account for a large proportion of sales, but these product brands cannot guarantee a stable source of supply. To ensure domestic orders, business suppliers usually use complex channels, therefore the price is difficult to control and gross profit is minimal. Some business platforms run out of stock and have no goods to provide. The cross-border e-commerce supply chain is long and complex, making each link very difficult to get through.

\section{Guangdong Province Cross-Border Electricity Suppliers Model Changes}

\section{Traditional Model}

(1) Overseas direct mail. This kind of model is the initial conservative pattern for suppliers. Direct mail can take full advantage of the high-quality global supply chain's logistics system. Suppliers need to pay much attention to integrated marketing and promotion, and brand awareness has to be emphasized in the process of selecting providers.

(2) Shopping guide with rebates/ Agency operation. One approach is technology oriented platforms, such as Meme and Hai360 in Sheena, that automatically obtain an overseas major electricity supplier's website, through processing technology. This is one of the first platforms set up in Guangzhou. Another approach is the proxy pattern. Chinese official websites contract directly with overseas corporations to operate on behalf of Chinese business. These two ways both have initial 
advantages. On the one hand, it is easy to set up with low cost and can solve the problem of information flow processing. On the other hand, it has rich SKU and easy to search for them. However, the weakness is that in the long term, core competitiveness is lacking and there is a need for real-time stock price updates and other technical requirements.

(3) Content sharing / Community information. This kind of platform can transform the potential users through content guidance. The advantage of overseas brands results in successful transactions, but it still requires a strong long-term supply chain capability.

\section{Traditional to Modern Mainstream Model}

(1) M2C mode: platform investment. Such sales model connected channels with network marketing effectively, so that products prices can be determined by the manufacturers directly, and then to the end consumers through M2C Unions. Typical platforms are, like Chuanli Network (Good Shopping Network), created and wholly owned by the Chuanli Guangdong Electronic Technology Co. Ltd. It is officially operating on January 16, 2013. Advantages are high user trust, authorized overseas qualifications, overseas direct mail and local provide services; Disadvantages are most of the them are TP-generation operations with high-price and weak brand control, generally speaking, this kind of mode is need to be improved further.

(2) B2C mode: self-bonded + direct purchase. Typical of these companies are like VIPSHOP in Guangzhou, as China's first self-B2C profitable achieved electricity suppliers, it relatively develops stably with a good trend. The advantages of these platforms lie in directly involving the sourcing organization, logistics and warehousing processes. Its sales turnover is high, timeliness is good, also typically attached to the "direct mail deals + flash sales" and other models as the complement to rich SKU and ease supply chain pressure. The disadvantage is that their categories are limited and they regard explosive ones as the main goods at present. In some areas, their independent customs limit the enter policies in which many of goods cannot be accepted (such as in Guangzhou, health care products and cosmetics cannot allowed into); at the same time, the pressure from the upstream supply chains, as well as in the process of clearance and financial barriers of self bonded warehousing is of great toughness for most cross-border suppliers.

(3) C2C mode: buy on behalf overseas. Typical platforms are Taobao worldwide, Meida Network in Guangzhou and We-business based on We-chat of Tecent in Zhenzhen. Although cross-border imports, through $\mathrm{C} 2 \mathrm{C}$ electronic business platforms, have many inherent problems, such as difficult to distinguish truth from falsehood and hard to tell between the original distributors and overseas buyers, all of those will cause a lot of contradictions. There is a long way to go to obtain the trust of consumers. The benefits of this model is easily to solve the problem of SKU, C2C model can facilitate precipitation in the spirit interactive level, meeting the meticulous, diversify, personalized needs of the customers. Outstanding buyers can use their strong sense of fashion to promote strong brands to obtain brands recognition and share values; they also can establish personal trust mechanism for the consumers domestic. The disadvantages lie in poor control of service experience since it traditionally rely on advertising and rebate mode, Private buying on behalf of others make individuals' purchasing risky in laws and policies. The key points are how to get traffic flow early and balance between users and to improve the scale of growth.

(4) BBC bonded mode: cross-border supply chain service providers, conducted by bonded mode to mail their products. Service providers cooperated with business platforms for delivery, the platform provides customer orders to supply chain service providers, and after getting those orders, cross-border providers mail goods directly to customers. Many of these service providers also offer supply chain financing services. Advantages are convenience and no pressure on the stock, 
disadvantages are BBC by means of cross-border electricity suppliers conducting general business, and long-term value is worried in the future.

\section{Analysis on the Development Trend of Cross-Border Electricity Suppliers in Guangdong Province under the Background of "One Belt and One Road"}

\section{Win-Win Situation in Competition with Capital-Driven}

Since October 2014, various companies began business in the fields of e-commerce. Some industry giants such as Jingdong, Netease, etc. have upgraded overseas shopping businesses to a strategic importance level. Start-up companies are absorbing more venture capital, such as Little Red Book, which has successively raised venture capital of U.S. \$ 10, 000, 000. Amazon started an on-line overseas purchase department that targeted the domestic market with international advantages. Logistics service providers lay the solid foundation for the industry through taking advantages of the industry strengths, beginning supply flows, and optimizing the supply chains.

\section{Shared Services and Integration of Resources}

The traditional e-commerce companies tend to develop independently of each other. Within the "One Belt and One Road "context, the use of computers will drive the connection between different industries with overseas capital. For instance, in the tourism industry, it can be combined with catering, taxi and other industries to achieve the integration of resources and shared services. Cross-border e-commerce business companies should learn to share the resources under the background of "One Belt and One Road”. Integration of resources should be composed of several aspects. Firstly, whole industry integration, such as mergers, consolidations and restructuring for the companies in the same industry. Secondly, supply chain integration, such as customs, trade, logistics and financial services platforms. Thirdly, a combination of traditional e-commerce companies cooperation through joint ventures and alliances.

\section{Strong Demand in the Multilingual and Trans-Regional Market}

Since the implementation of the "One Belt and One Road "strategy, China has increased trade with other countries along the way. The result is strong demand in multilingual and trans-regional markets leading to further development of national strategy, consequently suggesting more opportunities and growth potentials for cross-border e-commerce in other foreign markets. It is not uncommon to provide platforms related to local services in the foreign markets, for example, Ali-express opened a Portuguese website in the Brazilian markets that strengthens cooperation with local service providers in logistics and payment. International markets will be highly influenced by the electronic business platforms, since many of them have a huge demand for cheap Chinese goods with high quality. With an advanced economy in a coastal area, Guangdong Province should seize the opportunities to attract more attention in international markets in order to become the first one into those markets.

\section{Conclusions}

In April 2015, the FTA was established in Nansha, Guangdong Province, making Guangdong an honorary member of the World Federation of Free Trade. Under the background of "One Belt and One Road" strategic context, Guangdong's cross-border electricity trade will have prosperous prospects with enormous growth. Faced with the huge international and domestic markets, consumer demand will be more diversified. In the future, cross-border e-commerce will be a new driving force to promote the upgrading of industry. In this process, Guangdong Province should foster brand electronic business platforms and suppliers, build efficient logistics delivery systems to 
improve the competitiveness of local manufacturing, and optimize the industrial value chains as key objectives for future economic growth.

\section{ACKNOWLEDGEMENTS}

This work was supported in part by a grant from Guangdong province science and technology planning project. (2013B040404009)

\section{REFERENCES}

[1] Mobile commerce and online shopper behavior in China; Cross-border Ecommerce Country Report-China; http://www.thepaypers.com/ecommerce-facts-and-figures/china/14.

[2] Cross-Border Trade in Electricity; Werner Antweiler; 2014/5/9; Preliminary Version.

2015 China’s Cross-border Electricity Business Analysis Report; 2016/2/11; China's Ministry of Commerce. http://english.mofcom.gov.cn 